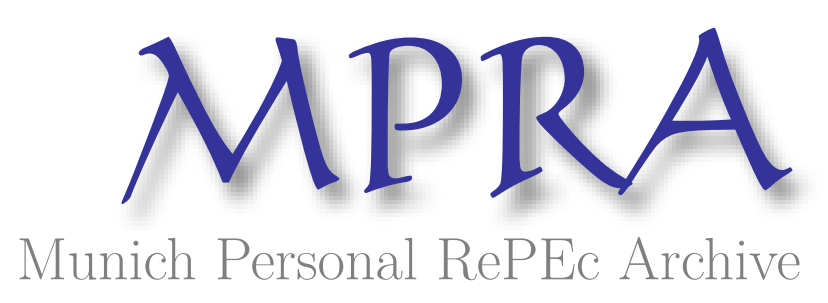

\title{
Border Effects and European Integration
}

Cheptea, Angela

INRA, UMR1302, F-35000 Rennes, France

February 2011

Online at https://mpra.ub.uni-muenchen.de/47009/

MPRA Paper No. 47009, posted 19 May 2013 07:18 UTC 


\title{
Economic Studies Conference
}

\author{
on
}

\section{Measuring Economic Integration}

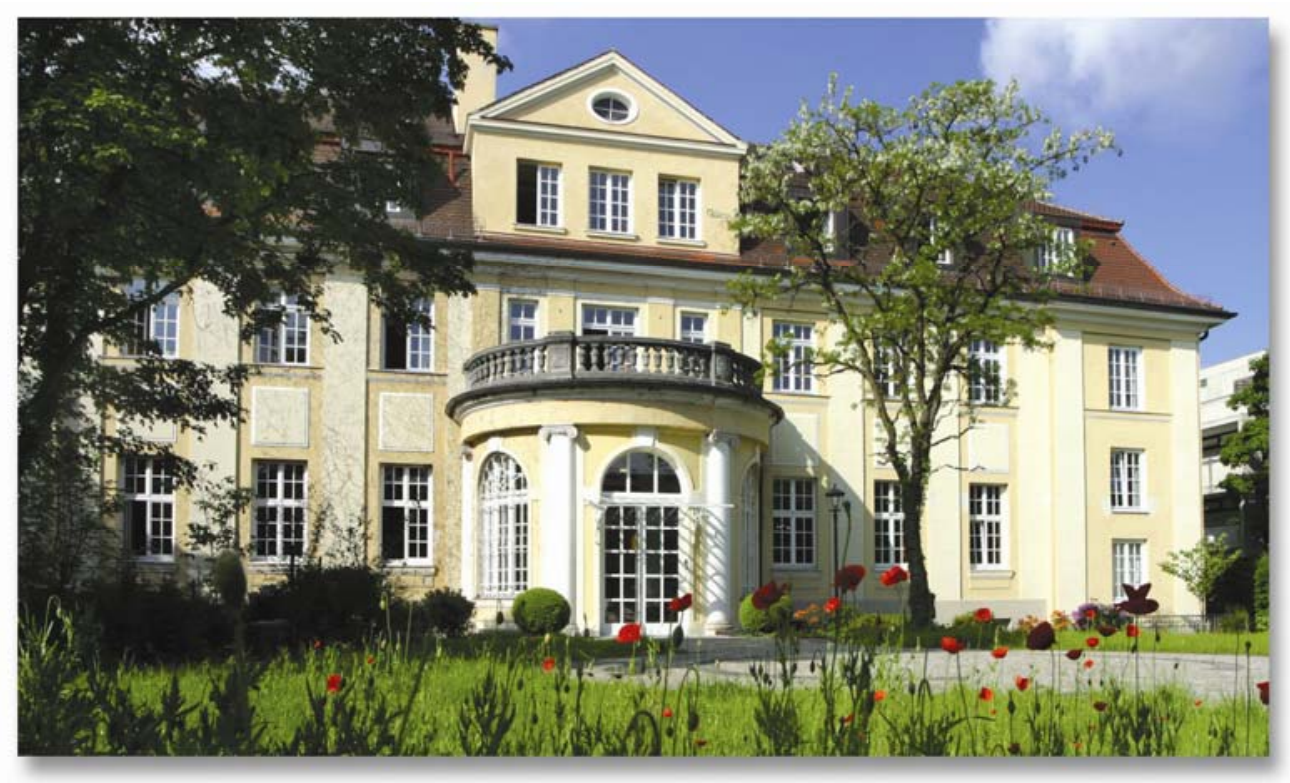

18 - 19 Februar 2011 CESifo Conference Centre, Munich

Border Effects and European Integration Angela Cheptea 


\title{
Border Effects and European Integration
}

\author{
Angela Cheptea*†
}

\begin{abstract}
A new method for measuring trade potential from border effects is developed and applied to manufactured trade between the old fifteen European Union (EU) members and twelve Central and East European (CEE) economies. Border effects are estimated with three theoretically compatible trade specifications, and much larger trade potentials are obtained than usually predicted by standard trade potential models. Even after a decade of regional trade liberalization, the integration of CEE and $\mathrm{EU}$ economies is two to three times weaker than intra-EU integration, revealing a large potential for East-West European trade.
\end{abstract}

Keywords : Trade potential, regional integration, border effects.

JEL Classification: F10, F12, F14, F15.

*INRA, UMR1302, F-35000 Rennes, France

${ }^{\dagger}$ AGROCAMPUS OUEST, UMR1302, F-35000 Rennes, France 


\section{$1 \quad$ Introduction}

Economic relationships between Central and Eastern European (CEE) countries and their Western partners during the 1990s have been marked by the premises of EU enlargement. In the early 1990s most CEE countries have formulated officially their desire to integrate the Union, and have received an affirmative response conditional on the fulfillment of several economic criteria. About a decade latter, they have acquired the membership status and benefit from all insiders' advantages. The evolution of their economic exchanges between these two dates reflected a gradual elimination of trade costs, and a concentration of trade with 'old' (core) EU partners. Regional integration between Eastern and Western European nations has been accompanied by important trade creation effects, that continue even after CEE countries have joined the European Union. Indeed, it takes time for firms to grasp trading opportunities offered by the modified economic environment. The economic literature employs the term trade potential to designate these effects.

The additional trade arising from an economic integration initiative is traditionally estimated in the literature by trade potential models that rely on the empirical success of the gravity equation. The essence of these models consists in comparing actual trade to the gravity-predicted or so-called "normal" level of trade, with the difference between the two capturing the trade potential. Wang and Winters (1991), Hamilton and Winters (1992), Baldwin (1993), Gross and Gonciarz (1996), Fontagné et al. (1999), Nilsson (2000), and Papazoglou et al. (2006) use this approach to estimate European trade potential during the 1990s. One drawback of this method is the misspecification of the gravity equation used in these models with respect to trade theory, and the sensitiveness of results upon the gravity specification employed. Another weakness of trade potential models is that they disregard the large amount of trade taking place inside national borders and base their predictions on an analysis carried exclusively on international trade.

The present paper introduces a new method for measuring trade integration and quantifying future increases in intra-regional trade. Differently from traditional trade potential models, I define the level of trade integration of two or more countries by referring to their domestic trade. The closer is the volume of trade between two countries to their domestic trade, when controlling for standard variables such as supply, demand, and trade costs, the more integrated are the two countries. In other words, I compute trade potentials from all cross-border trade costs, taking into account domestic trade.

Technically, the method consists of two steps. Firstly, I estimate the level of crossborder trade costs using each country's domestic trade as benchmark for its trade with partner countries. The rationale for this is the following: A country is a highly integrated and homogeneous economic space, where full economic integration is achieved. Indeed, in the light of some recent studies (e.g. Brunetti et al., 1997, Rauch, 2001), the presence of a single legislative system, central administration, currency, communication network and set of economic policies contributes to an important reduction of transaction costs and fosters exchange. This argument is confirmed by empirical works revealing that higher volumes of trade take place inside countries (i.e. within national borders) than between them (i.e. across borders). McCallum (1995) refers to this as the border effect and finds that even highly integrated countries as Canada and US trade about twenty times less with each other than with themselves. Later work has proven this figure to be unrealistically 
high: e.g. Anderson and van Wincoop (2003) find a border effect ranging between 2.24 and 10.7 for the same countries. Still, domestic trade remains a convenient benchmark for international trade flows. In this paper I make the assumption that trade costs other than those induced by the distance are null for transactions taking place within the same country, and express international trade costs in terms of border effects, i.e. the ratio of international-to-domestic volume of trade.

Secondly, I compare international trade costs for the integrating and the reference group of countries. The group of countries with the lowest level of intra-group trade costs serves as reference for all other regional trade flows. I compute the level of trade integration or trade potential as the ratio of estimated within- and cross-group border effects, with a lower ratio corresponding to a higher level of trade integration. I choose the reference group to be formed by countries with the lowest international trade costs and I assume that further integration within the region reduces trade costs to the level observed for the reference group. In the particular case of European integration, trade between the fifteen core-EU members is subject to lower distortions and I use it as a reference for other European flows, as in the literature on trade potentials. The fact that the share of intra-EU trade in total EU trade remained at a steady level during the last two decades suggests that the latter might well correspond to the long term equilibrium. The East-West European trade creation may or not be accompanied by trade diversion in the detriment of intraCEE integration. After the EU enlargement in 2004 and 2007 trade between new member states (NMS) became intra-EU trade, and trade costs associated with these flows should also converge, at least in the long run, to the level of intra-EU costs prior to enlargement.

Another question tackled in this paper is that of the correct specification of the gravity equation. Although gravity is shown to be compatible with both traditional and new trade theories, each theoretical model produces a different final trade specification. This aspect, ignored by trade potential models, is incorporated here through the use of theoretically derived trade equations in the estimation of border effects. One can estimate border effects from a national product differentiation setting as Anderson and van Wincoop (2003), with monopolistic competition and firm-specific varieties like Wei (1996) and Head and Mayer (2000), or, yet, estimate an average bilateral border effect as Head and Ries (2001). Accordingly, I use three alternative specifications for domestic and foreign trade flows. The first approach consists in using country-specific effects to capture importer and exporter groups of variables, allowing the estimation of coefficients on bilateral variables alone; the second involves the incorporation of a Dixit-Stiglitz-Krugman (DSK) monopolistic production model; and the last approach implies the computation of average trade 'freeness'.

Thus, the method presented in the current paper eliminates the two drawbacks characterizing the traditional trade potential models mentioned above: (i) the use of border specific costs permits to account for the fact that a lot of trade is already "missing" at the international level, and (ii) the estimation of border effects with theoretically derived trade equations corrects for specification problems. For the simplicity of the exposal I refer hereafter to trade between old/core EU countries as intra-EU trade, to trade between NMS that joined the $\mathrm{EU}$ in the last decade as intra-CEE trade, and to trade between the two groups of countries as CEE-EU or East-West European trade. Thus, the CEE-EU trade potential or trade integration is obtained as the ratio between the border effect estimated for CEE-EU trade and for intra-EU trade. 
Trade of the twelve NMS, both with other NMS and with the fifteen core-EU countries improved remarkably during the last decade of the twentieth century. The results predict much higher trade potential values for CEE-EU and intra-CEE trade than usually found in the literature with traditional trade potential models. Results are very robust, with the three theoretically sound specifications producing the same conclusions. Thus, at the beginning of the XXIst century trade between CEE and EU countries represented less than half of its attainable level, suggesting a possible two to three fold increase with further EU integration. The possible upsurge of intra-CEE trade in the following years, despite the impressive reduction of bilateral border effects reached by the beginning of the century, is even higher.

The paper is organized as follows. The next section describes the new trade potential measure introduced by this paper. Section 2 describes the theoretical trade model and three different specifications used to estimate border effects. Border effect estimates within and between country groups are presented and discussed in section 3. The main results of the paper are displayed in section 4. Trade potentials for European trade flows produced by the different approaches and their evolution in time are compared. Section 5 summarizes the conclusions.

\section{Theoretical Discussions}

I start by describing an underlying preference structure for trade in differentiated goods. The obtained trade equation includes variables that are unobserved or inaccurately measured, i.e. is unsuitable for direct estimations. To solve this issue I follow Combes et al. (2005) and consider three different trade specifications.

\section{A differentiated-goods trade structure}

First, I consider a trade structure with a differentiated good and $n_{i}$ varieties produced in each country $i$. The model has a slightly different interpretation depending on the used data. Each industry (when using industry-level data) or the entire manufactured sector (when using aggregate data) is considered to be composed of a single differentiated product of which multiple varieties are available. Product differentiation can be at country or firm level. National product differentiation was introduced by Armington (1969) who proposed an utility function in which consumers distinguish products by their origin. It can also arise from a Heckscher-Ohlin model with no factor price equalization as in Deardoff (1998). An alternative approach is that of Dixit-Stiglitz-Krugman (DSK) type monopolistic competition models. In the latter each variety is produced by a distinct firm, and the number of varieties $n_{i}$ (identical to the number of firms) is endogenously determined by the model.

Consumer preferences are homothetic and represented by a CES utility function. Importing country $j$ 's representative consumer utility is given by:

$$
u_{j}=\left[\sum_{i} n_{i}\left(a_{i j} x_{i j}\right)^{\frac{\sigma-1}{\sigma}}\right]^{\frac{\sigma}{\sigma-1}}
$$


with $a_{i j}$ representing country $j$ consumers' preference for country $i$ products, $x_{i j}$ the volume of goods produced in $i$ and consumed in $j$, and $\sigma$ the substitution elasticity between any two varieties. Coefficients $a_{i j}$ are introduced in order to allow for different preferences across countries. $^{1}$

I assume that consumers of each product are charged with the same price augmented by trade costs. The difference in the price of the same good in two different locations is therefore entirely explained by the difference in trade costs to these locations. For simplicity an 'iceberg' trade costs function is used. The price to country $j$ consumers of a good produced in $i, p_{i j}$, is the product of its mill price $p_{i}$ and the corresponding trade $\operatorname{cost} t_{i j}$. Two elements of bilateral trade costs are considered: transport costs proportional to the shipping distance $d_{i j}$, and costs due to the presence of trade barriers such as tariffs, non-tariff barriers, information costs, partner search costs, institutional costs, etc:

$$
t_{i j}=\underbrace{d_{i j}{ }^{\rho}}_{\begin{array}{c}
\text { transport } \\
\text { costs }
\end{array}} \underbrace{\exp \left[\left(1-h o m e_{i j}\right) b_{i j}\right]}_{\begin{array}{c}
\text { border-specific } \\
\text { costs }
\end{array}} .
$$

The second type of costs arise exclusively for trade across national borders. home $e_{i j}$ is a dummy variable equal to one for internal trade and to zero for trade between countries. $\left[\exp \left(b_{i j}\right)-1\right] \times 100$ gives the tariff equivalent of border-specific trade barriers on country $i$ exports to $j$. In section 3 I introduce a more complex trade costs function by decomposing the second left hand side term of equation (2) in order to account for the presence of a common land border or language, and different trade flows types.

Consumers of each country $j$ spend a total sum $E_{j}$ on domestic and foreign products:

$$
\sum_{i} n_{i} x_{i j} p_{i j}=E_{j}
$$

and choose quantities that maximize their utility function (1) under the budget constraint (3). Country $j$ 's total demand for country $i$ products is given by:

$$
\begin{gathered}
m_{i j} \equiv x_{i j} p_{i j}=a_{i j}^{\sigma-1}\left(\frac{p_{i} t_{i j}}{P_{j}}\right)^{1-\sigma} n_{i} E_{j}, \\
\text { where } \quad P_{j} \equiv\left[\sum_{k} a_{k j}^{\sigma-1}\left(p_{k} t_{k j}\right)^{1-\sigma} n_{k}\right]^{\frac{1}{1-\sigma}}
\end{gathered}
$$

is a price index of the importing country $j$ nonlinear with respect to the unknown parameter $\sigma$. The estimation of equations (4)-(5) is possible only for particular values of the substitution elasticity $\sigma$. But even then the presence of a non linear price index $P_{j}$, and the difficulty of measuring the number of varieties produced in each country limit the accuracy

\footnotetext{
${ }^{1}$ Two forms of preferences are usually found in the literature: identical for all countries, $a_{i j}=a_{i} \forall j$, yielding symmetric utility functions (e.g. Anderson and van Wincoop, 2003), and more pronounced for domestic products, $a_{i j}=\exp \left(e_{i j}\right)$ if $i \neq j$ and $a_{j j}=\exp \left(e_{j j}+\beta\right)$, producing asymmetric demand functions (e.g. Bergstrand, 1989, Head and Mayer, 2000).
} 
of results. Slightly different specifications are reached with national and firm level product differentiation.

I adopt the following notation $\phi_{i j} \equiv\left(t_{i j} / a_{i j}\right)^{1-\sigma}$, imported from the economic geography literature, and representing trade freeness (or $\phi$-ness). Consumer preferences can also be expressed as a function of bilateral variables, similar to trade costs. However, I have no means to disentangle the impact of the same variable on preferences from its impact on trade costs. Estimated coefficients on the latter will actually reflect the global effect on both trade costs and consumer preferences. For exposal simplicity I assume throughout the rest of the paper identical preferences for all products and consumers and interpret any increase (drop) in trade freeness as a reduction (raise) of trade costs. The main implication of this assumption is that our border effect measures will capture the trade gap arising from stronger preferences of consumers for domestic goods, in addition to the effect induced by larger costs for trading across cross-border. ${ }^{2}$ Alternatively, one could consider that an identical equally-priced good from source country $s$ is perceived differently by consumers in country $i$ and consumers in country $j$. A strong (weak) taste for good $s$ leads consumers to overvalue (undervalue) the virtues of the product and shifts their demand function upward (downward). Thus, the actual price to which respond consumers in country $j$ is $a_{s j}^{\sigma-1} p_{s j}$ rather than $p_{s j}$.

The rest of this section is reserved to the presentation and discussion of three alternative specifications of bilateral trade flows. The first consists in using country-specific effects to capture importer and exporter variables, allowing the estimation of coefficients on bilateral variables alone. We shall refer to it as the fixed-effects approach. The second procedure involves a deeper use of the theoretical framework, in particular the production side of a DSK monopolistic model, and the last approach refers to the computation of an average trade 'freeness'. We call those the odds and friction specifications, respectively.

\section{The fixed-effects specification}

The method presented bellow relies uniquely on the differentiated-goods structure presented above. As a result, it holds independently of the specific market structure and the production side assumptions, and is equally compatible with constant and increasing returns to scale, national and firm level differentiation of products. As implied by the name, it resides in using importer and exporter specific dummies to account for market and supply capacities, as in Rose and van Wincoop (2001) and Redding and Venables (2004).

An estimable trade specification can be derived directly from (4) by grouping $i$ and $j$ terms of the equation, using the definition of trade freeness, and taking logarithms on both sides:

$$
\ln m_{i j}=F E_{i}+\ln \phi_{i j}+F M_{j} .
$$

Country fixed effects are used as proxies for supply and demand terms of the equation with $F E_{i} \equiv \ln \left(n_{i} p_{i}^{1-\sigma}\right)$, and $F M_{j} \equiv \ln \left(E_{j} P_{j}^{\sigma-1}\right)$. Under this approach only bilateral

\footnotetext{
${ }^{2}$ The assumption of identical preferences does not alter the main conclusion of the paper. The aim of the paper is to illustrate the integration between old and new EU countries over the past two decades. While differences in consumer preferences may inflate the level of border effects estimated for each year, they leave unaffected the evolution trend. Indeed, changes in tastes and consumption habits arise on much longer time horizons than the one considered in the paper.
} 
variables are left in the equation, and all structural parameters, in particular the elasticity of substitution between varieties $\sigma$, cannot be estimated. This represents the major drawback of this approach.

Differently from the cited authors, I am interested in the estimation of border specific effects and estimate equation (6) for international and domestic trade. Trade costs in $\phi_{i j}$ are decomposed according to (2) to reach the final trade specification:

$$
\ln m_{i j}=F E_{i}+F M_{j}+\rho(1-\sigma) \ln d_{i j}+(1-\sigma) b_{i j}-(\sigma-1) b_{i j} h o m e_{i j} .
$$

Accordingly, a higher coefficient on the last variable designates higher cross-border barriers for country $i$ 's exports to $j$. As suggested by equation (7) higher trade barriers can arise not only from larger trade costs (larger $b_{i j}$ ), but also from a higher elasticity of substitution. The trade loss due to country-specific trade barriers (e.g. strong non-tariff barriers, poor domestic institutions) is seized by country specific effects and not by the border effect.

Differently, one can first derive a gravity-type trade equation following Anderson and van Wincoop (2003)'s approach for national product differentiation, and only afterwards group supply and demand variables separately into country specific effects. This will produce identical estimation equations and results; the difference lays in the interpretation of country and partner effects $F E_{i}$ and $F M_{j}$.

Summing bilateral imports (4) across destinations gives the production level at origin $y_{i}$. Then the obtained identity can be further used to express the unknown amount $p_{i}{ }^{1-\sigma}$ $\left(n_{i}=1, \forall i\right.$ in this particular case), which is then re-introduced in the trade equation (4). Differently from Anderson and van Wincoop (2003), this can be accomplished without imposing market clearance $\left(y_{i}=E_{i}\right)$ and using data on importer's expenditure. ${ }^{3}$ A nice gravity equation is thus obtained: ${ }^{4}$

$$
\begin{gathered}
m_{i j}=\frac{y_{i} E_{j} \phi_{i j}}{\bar{P}_{i}^{1-\sigma} \tilde{P}_{j}^{1-\sigma}} \\
\text { with } \quad \bar{P}_{i}^{1-\sigma} \equiv \sum_{k} \phi_{i k} P_{k}^{\sigma-1} E_{k}, \quad \text { and } \quad \tilde{P}_{j}^{1-\sigma}=\sum_{k} p_{k}^{1-\sigma} \phi_{k j} .
\end{gathered}
$$

$\tilde{P}_{j}$ is an importer-specific price index reflecting the average price of country $j$ 's imports. A higher average price paid by consumers of the importing country increases the value of exports to that market. $\tilde{P}_{j}^{1-\sigma}$, on the contrary, corresponds to the relative isolation of a country in terms of trade costs and/or consumer preferences, and reduces bilateral flows. $\bar{P}_{i}$ is an exporter-specific weighted average of price indexes of all its trading partners including itself. The expression of $\bar{P}_{i}^{1-\sigma}$ in (9) is very similar to the remote market access

\footnotetext{
${ }^{3}$ Market clearance is a quite restrictive assumption for it implies balanced international trade, which occurs only at national level and in the long run. This assumption is not completely inconsistent with the CEE-EU industry level pattern of trade. In $200080 \%$ of the trade between EU and CEE countries at the industry level was intra-industry trade. Trade imbalances are less important for the entire manufactured sector, but not sufficiently low to suggest that realistic predictions shall be obtained by assuming market clearance at aggregate level. Therefore, I use expenditure data computed as the sum of domestic production and foreign imports.

${ }^{4}$ Deardorff (1998) reaches a similar trade equation from a Heckscher-Ohlin trade model with differences in factor prices across countries and complete specialization.
} 
used in economic geography models: the access of country $i$ 's products to all markets, including the domestic one. In other words, $\bar{P}_{i}$ reflects the purchasing power of $i$ 's partners and is positively related to trade. An improved global market access for country $i$ products translates by higher total shipments to its partners. Symmetric trade costs $\left(t_{i j}=t_{j i}, \forall i, j\right)$, and identical preferences across countries $\left(a_{i j}=a_{i}, \forall i, j\right)$ yield the symmetric solution $\bar{P}_{i}=\tilde{P}_{i}$ used by Anderson and van Wincoop (2003) to reach a more elegant version of (8). In our specific case of East-West European trade this assumption is irrelevant because the two groups of countries followed uneven trade liberalization timetables, a difference that I attempt to measure in the following sections.

Writing equation (8) in logarithmic form and using country and partner binary variables to capture demand and supply terms ${ }^{5}$, I reach again equation (6).

\section{The odds specification}

This subsection presents an alternative trade model with monopolistic competition as in Dixit and Stiglitz (1977) and Krugman (1980), increasing returns to scale and firm-level differentiated products. Similar trade models have been developed by Head and Ries (2001) and Head and Mayer (2000). In a DSK setting firms set prices as if they face a constant price elasticity of demand, equal to the elasticity of substitution between two varieties $\sigma$. Their prices, free of trade costs, are expressed as a constant markup over the marginal cost of production $c_{i}$ :

$$
p_{i}=c_{i} \frac{\sigma}{\sigma-1}
$$

I consider labor as the unique factor of production and a single equilibrium wage level $w_{i}$ within any given country $i$. Then a unique mill price is charged for all varieties produced in the same country. Production technologies are assumed identical across countries and wages are the only source of difference in production costs. Identical production functions $q p_{i}=F w_{i}+\mu q w_{i}$ are considered, with the first term on the right hand side expression denoting fixed costs and the second term marginal costs, both expressed in units of labor. Firms enter the market until all profits vanish away, and the equilibrium price equals the average cost. This implies equal outputs $q$ for all firms and varieties:

$$
q=\frac{F(\sigma-1)}{\mu}
$$

where $F$ and $\mu$ represent invariable fixed and marginal costs in labor units. The number of varieties produced and firms in each country, $n$, is endogenous to the model. Combining equations (10) and (11), and using the fact that a country's revenue $y_{i}$ is the sum of its firms' revenues, one can express the number of varieties produced by a country as follows:

$$
n_{i}=\frac{y_{i}}{w_{i} \sigma F}
$$

\footnotetext{
${ }^{5} F E_{i} \equiv \ln \left(y_{i} \bar{P}_{i}^{\sigma-1}\right)$ and $F M_{j} \equiv \ln \left(E_{j} \sum_{k} p_{k}^{1-\sigma 1} \phi_{k j}\right)$.
} 
Given the expression of the number of locally produced varieties, equation (4) rewrites to:

$$
\begin{gathered}
m_{i j}=p_{i}^{1-\sigma} \frac{\phi_{i j}}{P_{j}^{1-\sigma}} \frac{y_{i} E_{j}}{\sigma w_{i} F}, \\
\text { with } \quad P_{j}^{1-\sigma}=\sum_{k} p_{k}^{1-\sigma} \phi_{k j} \frac{y_{k}}{\sigma w_{i} F} .
\end{gathered}
$$

Using relative demands as explained variables, i.e. the ratio of trade flows to the same destination, considerably simplifies the specification by eliminating destination specific right hand side terms. Applied to our trade equation (13) this means the elimination of non linear importer's price index and expenditure. Thus the set of explained variables shrinks to the characteristics of the two origins. Particularly interesting for us is the case when the destination country is taken as reference. With bilateral flows given by equation (13), the foreign-to-internal trade ratio becomes:

$$
\frac{m_{i j}}{m_{j j}}=\frac{y_{i}}{y_{j}}\left(\frac{p_{i}}{p_{j}}\right)^{1-\sigma} \frac{w_{j}}{w_{i}} \frac{\phi_{i j}}{\phi_{j j}} .
$$

Note that assumptions on the production side imply that mill prices are equal to $p_{i}=$ $\mu w_{i}(\sigma /(\sigma-1))$. The price ratio in (15), which can also be written as the ratio of marginal costs, becomes equal to the wage ratio. Unknown technological $F$ and $\mu$ coefficients simplify when using relative demands.

Border specific costs can be estimated from equation (15) with destination country as reference and the sample restricted to foreign-relative-to-domestic shipments (exclude observations of the $m_{j j} / m_{j j}$ type). Use the decomposition of trade costs (2) in (15) and take logarithms to obtain the odds specification:

$$
\ln \frac{m_{i j}}{m_{j j}}=\ln \frac{y_{i}}{y_{j}}-\sigma \ln \frac{w_{i}}{w_{j}}+\rho(1-\sigma) \ln \frac{d_{i j}}{d_{j j}}+(1-\sigma) b_{i j}
$$

The opposite of the constant term in the above equation reflects border-specific trade barriers. 'Missing' international trade is measured in terms of actual domestic trade, i.e. as the ratio of domestic-to-cross-border trade deflated by relative production, wage and distance. More specifically, the border effect for imports of $j$ from $i$ is obtained from (16) by taking the exponential of the negative free term: $\exp \left[(\sigma-1) b_{i j}\right]$.

If consumer preferences were to vary with the goods' origin, any disproportionate preference for domestic varieties would be captured by the border effect. With a generally accepted perception of positive domestic biases in preferences, one should expect larger border effects estimates with the odds specification.

\section{The friction specification}

The last approach regards the use of a transformation of the explained variable introduced by Head and Ries (2001). They use as left hand side variable the inverse index of 'friction' 
to trade, defined as:

$$
\Phi_{i j}=\left(\frac{m_{i j}}{m_{j j}} \frac{m_{j i}}{m_{i i}}\right)^{1 / 2}
$$

It reflects the geometric mean of foreign firms' success relative to domestic firms' success in each home market. Head and Ries (2001) assimilate the inverse of this index to the actual border effect between Canada and the United States.

To stay consistent with the theoretical setup described in the beginning of this section, trade flows in the expression of $\Phi_{i j}$ are replaced using equation (4). Take logarithms on both sides to obtain:

$$
\ln \Phi_{i j}=\ln \left(\frac{\phi_{i j}}{\phi_{j j}} \frac{\phi_{j i}}{\phi_{i i}}\right)^{1 / 2}
$$

Equation (18) can also be obtained following the same steps directly from (8) or even (15). Its application is not therefore restricted to a specific market structure. According to the above specification, index $\Phi_{i j}$ actually represents the average trade freeness between countries $i$ and $j$ relative to their internal freeness. In the light of economic geography literature which assumes unitary internal freeness (null internal trade costs) and symmetric trade costs, the inverse friction index $\Phi_{i j}$ becomes precisely the trade freeness $\phi_{i j}$.

Note that equation (18) imposes unitary coefficients on production variables, as suggested by the theory, and is therefore more in line with theoretical predictions than the previous two approaches. However, it allows only for the estimation of the average border effect for any two trading partners, rather than for two distinct effects, one for each trade directions. Use the expression of trade costs (2) in the above equation to get:

$$
\ln \Phi_{i j}=\rho(1-\sigma) \ln \frac{d_{i j}}{\left(d_{j j} d_{i i}\right)^{1 / 2}}+(1-\sigma)\left(\frac{b_{i j}+b_{j i}}{2}\right)
$$

Another advantage of the friction specification is that it removes the need of using even origin specific variables, which is an important gain when accurate production, price and/or wage data is not available. As previously, the constant term refers to the magnitude of border effects when unitary trade friction observations are excluded. It captures as well any bias in consumer preferences of both importing and exporting markets when preferences are allowed to vary across countries.

Border effects under all specifications have two components: one reflecting the true level of international trade costs $\left(b_{i j}\right.$ for the first two approaches and $\left(b_{j i}+b_{i j}\right) / 2$ for friction $)$, and another coming from the elasticity of substitution between variables $(\sigma-1)$. This means that even very small trade barriers may generate important deviations of trade towards the domestic market when the substitution elasticity is sufficiently high. None of the specifications presented in this section permits the estimation of all structural parameters. Therefore, I can only estimate overall border effects with each approach, without being able to distinguish the part ascribed to each of the two elements. In the fixed-effects specification unilateral origin and destination trade costs are reflected in country and partner fixed effects. The last two trade equations, therefore, might produce larger estimates of $b_{i j}$. In the next section I proceed to the estimation of European border effects using the three trade specifications introduced above and McCallum (1995)'s standard (atheoretical) gravity. 


\section{Estimating Border Effects Across Europe}

The method proposed in this paper computes trade potentials from border effects within and between country groups. This section is dedicated to the estimation of border effects. I divide trade between European countries into four types: EU imports from CEE, CEE imports from EU, intra-EU trade, and intra-CEE trade, and estimate border effects for each type of flows. I use a single equation on the entire sample of countries to estimate the four border effects. This method is preferred to estimating border effects separately for each type of trade since it has the advantage of imposing the same coefficients of independent variables for all trade types and yields more comparable results. Border effects are estimated with the fixed-effects, odds, and friction specifications presented in section 2. For comparison, I estimate two additional specification: a simple gravity equation only on cross-border trade flows within the sample, and a simple gravity equation on both domestic and foreign flows as in McCallum (1995). Estimations are carried separately for total manufactured imports and for industry level imports.

I introduce a more complex structure of trade costs by decomposing the last term of equation (2) and allowing for differences across the type of trade and for countries sharing a land border or speaking the same language:

$$
\begin{aligned}
\ln t_{i j}= & \delta \ln d_{i j}+b_{0} \text { home }_{i j}+b_{1} C E \text { EtowardsEU } U_{i j}+b_{2} \text { EUtowardsCEE }_{i j} \\
& +b_{3} \text { intraEU }_{i j}+b_{4} \text { intraCE }_{i j}+c_{1} \text { contig }_{i j}+c_{2} \text { comlang }_{i j}
\end{aligned}
$$

As previously, home ${ }_{i j}$ stands for domestic trade and $b_{0}<0$. Dummies $C E E t o w a r d s E U_{i j}$, $E U$ towardsCEE $E_{i j}$, intraEU $U_{i j}$, intraCEE $E_{i j}$ indicate the affiliation of each observation to a particular trade type. Variables contig $_{i j}$ and comlang $_{i j}$ denote respectively a common land border and language for countries $i$ and $j$. As both linguistic and neighbor relations are likely to reduce trade costs, I expect coefficients $c_{1}$ and $c_{2}$ to be negative. Observe that the first fixe dichotomic variables in the above trade costs specification sum to unity. The use of (20) along with a constant term in a trade equation does not permit therefore the estimation of all parameters. I choose to drop the variable $h o m e_{i j}$ and use domestic trade as reference for the estimation of coefficients $b_{1}$ through $b_{4}$. Thus, the constant term reflects the level of domestic trade and the other trade flows are expressed as deviations from this level. In the odds and friction specification lower trade costs for domestic shipments are directly accounted for by the specific form of the left hand side variable, and dummy home $_{i j}$ becomes irrelevant.

I use a gravity equation similar to that of McCallumn (1995) as baseline:

$$
\begin{aligned}
\ln m_{i j}= & \alpha_{0}+\alpha_{1} \text { rrod }_{i}+\alpha_{2} \text { cons }_{j}+\alpha_{3} d_{i j}+\beta_{1} \text { CEEtowardsEU } \\
& +\beta_{2} \text { EUtowardsCEE }_{i j}+\beta_{3} \text { intraEU }_{i j}+\beta_{4} \text { intraCEEij } \\
& +\gamma_{1} \text { contig }_{i j}+\gamma_{2} \text { comlang }_{i j}+\epsilon_{i j}
\end{aligned}
$$

Exporter's production prod $_{i}$ and importer's consumption cons $s_{j}$ are used as proxies for national revenues. The border effect for each type of trade is obtained as the exponential of the absolute value of the corresponding coefficient. For example, $\exp \left(-\beta_{1}\right)$ shows how much more does in average a EU member state buy from itself than from other EU countries. 
I estimate equation (21) separately on international flows and on domestic and international flows. In the first case variables home $i j$ and intraEU $U_{i j}$ are dropped due to collinearity with other dummies and trade flows are expressed as deviations from intra-EU trade (captured by the constant term). This specification does not permit to estimate border effects and serves only for comparison of other estimates. It is used in section 4 to compute benchmark trade potentials since similar specifications are used in the traditional trade potential literature.

The trade equation estimated with the fixed-effects procedure is obtained by integrating the more detailed trade costs function (20) in equation (6). However, the use of all group dummies, country and partner specific effects is impossible due to collinearity problems. The inclusion of all country specific effects is imperative for the estimation of average effects for the entire sample, not relative to an excluded country pair. But then variable home $_{i j}$ can be obtained as a linear combination of other group, country, and partner dummies. A tractable equation is reached by replacing the variables $C E E t o w a r d s E U_{i j}$ and EUtowardsCEE $E_{i j}$ by their sum, $C E E$ and $E U_{i j}$ :

$$
\begin{aligned}
\ln m_{i j}= & F E_{i}+F M_{j}+\alpha \ln d_{i j}+\beta_{0}+\beta_{12} C E E \text { EandEU } U_{i j}+\beta_{3} \text { intraEU }_{i j} \\
& +\beta_{4} \text { intraCEE }_{i j}+\gamma_{1} \text { contig }_{i j}+\gamma_{2} \text { comlang }_{i j}+\varepsilon_{i j}
\end{aligned}
$$

In this case one can estimate only an average border effect for CEE-EU trade: $\exp \left(-\beta_{12}\right)$. With lower relative trade costs for EU countries $\left(b_{1}<b_{2}\right)$, this method underestimates the border effect for intra-EU trade and overestimates the effect for trade between NMS.

The odds trade specification is reached by combining equations (16) and (20):

$$
\begin{aligned}
\ln \frac{m_{i j}}{m_{j j}}= & \alpha_{1} \ln \frac{y_{i}}{y_{j}}+\alpha_{2} \ln \frac{w_{i}}{w_{j}}+\alpha_{3} \ln \frac{d_{i j}}{d_{j j}}+\beta_{0}+\beta_{1} C E \text { EtowardsE} U_{i j} \\
& +\beta_{2} \text { EUtowardsCEE }_{i j}+\beta_{3} \text { intraEU }_{i j}+\beta_{4} \text { intraCE } E_{i j} \\
& +\gamma_{1} \text { contig }_{i j}+\gamma_{2} \text { comlang }_{i j}+v_{i j}
\end{aligned}
$$

Relative production values are used for output or revenue ratios. Of all specifications exposed in section 2, this is the only one that estimates distinct border effects for each of the four European trade types.

The friction approach estimates average two-way trade within and between the two groups of countries. Differently from the fixed-effects method, dummies for both CEE exports to and imports from EU are included. By construction, the coefficients on these variables are equal and reflect the average CEE-EU border effect. The equation estimated with this approach is the following:

$$
\begin{aligned}
\ln \Phi_{i j}= & \alpha \ln \frac{d_{i j}}{\sqrt{d_{j j} d_{i i}}}+\beta_{0}+\beta_{1} C E \text { EtowardsEU } U_{i j}+\beta_{2} \text { EUtowardsCEE }_{i j} \\
& +\beta_{3} \text { intraEU }_{i j}+\beta_{4} \text { intraCEE }_{i j}+\gamma_{1} \text { contig }_{i j}+\gamma_{2} \text { comlang }_{i j}+v_{i j}
\end{aligned}
$$

Coefficients $\beta_{1}$ to $\beta_{4}$ may also capture the share of consumer preferences common to all countries of each group, including any particular preference for domestic products, common to all EU countries, and respectively all NMS. The use of relative demands in the last 
two specifications introduces spatial autocorrelation in the error term. This is corrected through a robust clustering procedure, which allows a correlation of residuals $v_{i j}$ for the same importing country $j$.

I estimate border effects for total manufactured bilateral imports of fifteen EU countries and twelve Central and East European countries with pooled ordinary least squares and year fixed effects and report results in table 1. Standard deviations are obtained with a robust clustering technique that allows error terms for the same country pair to be correlated. This permits to control at least partially for autocorrelation in the data. All coefficients have the expected sign and most of them are statistically significant. Production and consumption coefficients are close to unity and the distance elasticity of trade is not very different from -1, similar to most empirical studies in the literature. The parameters of interest are the coefficients on group (trade type) dichotomic variables. The fist column shows estimates of international trade costs relative to intra-EU costs. Negative coefficients of group dummies indicate that intra-EU trade is subject to lowest trade costs, justifying its use as reference for other European trade flows. A core EU country exports on average $37 \%[=(1-\exp (-0.46)) \times 100]$ less to a NMS than to another EU country, imports $40 \%[=(1-\exp (-0.51)) \times 100]$ less from a NMS than from a EU partner, and two NMS trade $43 \%[=(1-\exp (-0.57)) \times 100]$ less than two core EU countries equally large and distant. Border effect estimates obtained with equation (21) are presented in column 2. Setting all group variables equal to zero yields an estimation of domestic trade and trade costs for each type of international trade flows are obtained relative to this reference level. Thus, intra-EU border effects or trade costs are $5.5[=\exp (1.71)]$ times larger than domestic trade costs; EU exports to and imports from NMS are $9.0[=\exp (2.20)]$ and respectively $9.6[=\exp (2.26)]$ times more expensive than trading within national borders. Trade costs between NMS from Central and Eastern Europe are the largest: $10.5[=\exp (2.35)]$ times domestic costs. Hence, both CEE-EU and intra-CEE trade integration lies bellow the level reached by the fifteen core-EU members.

The positive and significant coefficient on the common land border variable confirms the intuition that neighbor countries trade more with each other. This can be due to lower trade costs between these countries, as well as to more similar consumer preferences. The non significant coefficient of the common language dummy is due to its high correlation with the common border variable, the low number of dyads sharing both characteristics in the sample, and their uneven distribution across country groups. ${ }^{6}$ Including internal trade in estimations (column 2) keeps the coefficients on all variables almost unchanged (relative to column 1), and sets forward the fact that both EU and CEE countries rely much more on domestic than foreign partners.

Border effects of similar magnitude of are obtained with the other three trade specifications. The fixed-effects model (column 3) estimates that a EU member country buys on average about $3.8[=\exp (1.34)]$ times more from itself than from another EU country, while a similar NMS buys about $15.5[=\exp (2.74)]$ times more. Trade between EU and NMS is less than half of the intra-EU trade, when controlling for market and supply capacities, distance and common language and land border.

\footnotetext{
${ }^{6}$ Indeed, in Europe most countries that speak the same language share also a land border: e.g. Austria and Germany, Belgium and its neighbors. Out of the 650 distinct country-partner relationships in the panel only 20 speak a common language, and 14 of them are core EU countries.
} 
Table 1: European trade integration: total manufactured imports

\begin{tabular}{|c|c|c|c|c|c|c|}
\hline $\begin{array}{l}\text { Model : } \\
\text { Dependent variable: }\end{array}$ & $\begin{array}{c}(1) \\
\text { gravity } \\
\ln m_{i j}\end{array}$ & $\begin{array}{c}(2) \\
\text { gravity } \\
\ln m_{i j}\end{array}$ & $\begin{array}{c}(3) \\
\mathrm{FE} \\
\ln m_{i j}\end{array}$ & $\begin{array}{c}(4) \\
\text { odds } \\
\ln \frac{m_{i j}}{m_{i j}}\end{array}$ & $\begin{array}{c}(5) \\
\text { odds IV } \\
\ln \frac{m_{i j}}{m_{i j}}\end{array}$ & $\begin{array}{c}(6) \\
\text { friction } \\
\Phi_{i j}\end{array}$ \\
\hline ln production exporter & $\begin{array}{c}0.84^{a} \\
(0.03)\end{array}$ & $\begin{array}{l}0.83^{a} \\
(0.02)\end{array}$ & & & & \\
\hline ln consumption importer & $\begin{array}{l}0.74^{a} \\
(0.03)\end{array}$ & $\begin{array}{l}0.73^{a} \\
(0.02)\end{array}$ & & & & \\
\hline ln distance & $\begin{array}{r}-1.09^{a} \\
(0.06)\end{array}$ & $\begin{array}{c}-1.07^{a} \\
(0.06)\end{array}$ & $\begin{array}{c}-1.11^{a} \\
(0.06)\end{array}$ & & & \\
\hline ln relative production & & & & $\begin{array}{c}0.79^{a} \\
(0.05)\end{array}$ & 1.00 & \\
\hline ln relative wage & & & & $\begin{array}{c}-0.29^{b} \\
(0.11)\end{array}$ & $\begin{array}{c}-0.43^{a} \\
(0.11)\end{array}$ & \\
\hline In relative distance & & & & $\begin{array}{c}-0.72^{a} \\
(0.15)\end{array}$ & $\begin{array}{l}-0.88^{a} \\
(0.15)\end{array}$ & \\
\hline ln average relative distance & & & & & & $\begin{array}{c}-0.90^{a} \\
(0.05)\end{array}$ \\
\hline CEE exports to EU & $\begin{array}{c}-0.51^{a} \\
(0.09)\end{array}$ & $\begin{array}{c}-2.26^{a} \\
(0.22)\end{array}$ & & $\begin{array}{c}-3.36^{a} \\
(0.36)\end{array}$ & $\begin{array}{l}-2.70^{a} \\
(0.35)\end{array}$ & $\begin{array}{r}-2.70^{a} \\
(0.13)\end{array}$ \\
\hline EU exports to $\mathrm{CEE}$ & $\begin{array}{c}-0.46^{a} \\
(0.08)\end{array}$ & $\begin{array}{c}-2.20^{a} \\
(0.22)\end{array}$ & & $\begin{array}{c}-2.89^{a} \\
(0.46)\end{array}$ & $\begin{array}{c}-2.74^{a} \\
(0.50)\end{array}$ & $\begin{array}{c}-2.70^{a} \\
(0.13)\end{array}$ \\
\hline CEE-EU & & & $\begin{array}{r}-2.17^{a} \\
(0.22)\end{array}$ & & & \\
\hline intra EU & & $\begin{array}{c}-1.71^{a} \\
(0.23)\end{array}$ & $\begin{array}{c}-1.34^{a} \\
(0.29)\end{array}$ & $\begin{array}{c}-2.22^{a} \\
(0.32)\end{array}$ & $\begin{array}{c}-1.86^{a} \\
(0.34)\end{array}$ & $\begin{array}{c}-1.81^{a} \\
(0.12)\end{array}$ \\
\hline intra CEE & $\begin{array}{r}-0.57^{a} \\
(0.12)\end{array}$ & $\begin{array}{c}-2.35^{a} \\
(0.21)\end{array}$ & $\begin{array}{l}-2.74^{a} \\
(0.25)\end{array}$ & $\begin{array}{c}-3.61^{a} \\
(0.38)\end{array}$ & $\begin{array}{c}-3.20^{a} \\
(0.37)\end{array}$ & $\begin{array}{c}-3.15^{a} \\
(0.15)\end{array}$ \\
\hline common land frontier & $\begin{array}{c}0.31^{b} \\
(0.13)\end{array}$ & $\begin{array}{c}0.36^{a} \\
(0.13)\end{array}$ & $\begin{array}{c}0.36^{a} \\
(0.13)\end{array}$ & $\begin{array}{c}0.83^{a} \\
(0.19)\end{array}$ & $\begin{array}{c}0.61^{a} \\
(0.20)\end{array}$ & $\begin{array}{c}0.57^{a} \\
(0.12)\end{array}$ \\
\hline common official language & $\begin{array}{c}0.06 \\
(0.25)\end{array}$ & $\begin{array}{c}0.06 \\
(0.24)\end{array}$ & $\begin{array}{c}0.22 \\
(0.25)\end{array}$ & $\begin{array}{l}0.46^{b} \\
(0.18)\end{array}$ & $\begin{array}{l}0.49^{a} \\
(0.17)\end{array}$ & $\begin{array}{l}0.51^{b} \\
(0.21)\end{array}$ \\
\hline $\begin{array}{l}\mathrm{N} \\
\mathrm{R}^{2} \\
\text { Year fixed effects } \\
\text { Durbin-Wu-Hausman } \chi_{2} \\
\text { p-value }\end{array}$ & $\begin{array}{c}8360 \\
0.91 \\
\text { yes }\end{array}$ & $\begin{array}{c}8701 \\
0.92 \\
\text { yes }\end{array}$ & $\begin{array}{c}9434 \\
0.92 \\
\text { yes }\end{array}$ & $\begin{array}{c}7987 \\
0.80 \\
\text { yes }\end{array}$ & $\begin{array}{c}7987 \\
0.67 \\
\text { yes } \\
29.87 \\
0.000 \\
\end{array}$ & $\begin{array}{c}8317 \\
0.72 \\
\text { yes }\end{array}$ \\
\hline
\end{tabular}

Note: Standard errors in parentheses: ${ }^{a},{ }^{b}$ and ${ }^{c}$ represent respectively statistical significance at the $1 \%, 5 \%$ and $10 \%$ levels.

The next two columns present results from the odds approach. Figures in column 4 correspond to estimates of equation (23) with generalized least squares; in column 5 I correct for endogeneity induced by the simultaneous use of production and wage variables and revealed by a significant Durbin-Wu-Hausman statistic. I impose a unitary coefficient 
on relative production, in line with the theoretical model, and use per capita GDP, employment levels (size of labor force), and productivity as instruments for wages. Standard errors take into account the correlation of the error terms for a given importer. This is required by the specific form of the explained variable: the logarithm of the ratio between a imports from a foreign source and domestic purchases. All estimates are statistically significant at the $5 \%$ level. The low absolute value of the wage coefficient is due to the fact that wages reflect quite poorly product prices. ${ }^{7}$ I obtain larger absolute values for wage and distance coefficients when I correct the endogeneity bias. The use of instrumental variables (IV) also induces a drop in European border effects, which approach the estimates of the fixed-effects model. Column 4 results confirm the relationship between CEE-EU trade costs in both directions established in columns 1 and 2: It costs less for EU countries to export to CEE partners than for NMS from Central and Eastern Europe to export to old EU. This difference vanishes with a IV estimator: CEE-EU trade in either direction is about fifteen times more expensive than trade with a domestic partner. Core EU countries with no common border or language trade with each other six times more than with themselves. More similar tastes and/or larger transaction costs lead to a higher border effect estimate for intra-CEE trade: $24.5[=\exp (3.20)]$.

The last column of table 1 displays the estimates of the friction specification. Bilateral variables used to express trade costs are the only explanatory variables in this model. By construction, error terms are not independent across observations, but are assumed independent across importer-exporter couples. Estimates of border effects are very similar to the ones in column 5. The last three columns also show an enhanced effect of the common land border and confirm that countries that speak the same language face lower trade costs. As expected, the odds and friction specifications generate larger border effects than the fixed-effects and standard gravity models. This difference is explained by the fact that in the fixed-effects approach importer and exporter dummies capture country-specific trade costs as well as some of the variance in consumer preferences, while in the odds and friction specifications they are attributed to border effects. Therefore, if one believes that country-specific trade costs have are uniformly distributed and consumer preferences are highly uneven, one should rely on estimates in column 3. Estimates from columns 5 and 6 should be preferred in the opposite case. To summarize, depending on the specification, CEE-EU trade is on average 9 to 15 times inferior to domestic trade when keeping supply, demand, and trade costs constant. This ratio is 2.4 times larger than for trade between the old EU countries, but represents less than two-thirds of the similar ratio for intra-CEE trade.

Border effect estimates obtained with industry level data are shown in table $2{ }^{8}$ When trade is broken down by industries, an important number of zero value trade flows is observed. The problem with nil trade flows is that they do not occur randomly, but are the outcome of a selection procedure, e.g. a low supply or demand for a particular group of products. To correct for this sample self-selection bias I give a positive weight to the zero trade mass and employ a two-stage Heckman estimator: a first-stage probit model and a second-stage pooled OLS model with year fixed effects. A statistically significant

\footnotetext{
${ }^{7}$ In reality the labor is not the unique factor of production and there are many additional distortions in the price structure not captured by the model.

${ }^{8}$ Point estimates of all coefficients can be provided upon request.
} 
Table 2: European trade integration: border effects with industry-level data

\begin{tabular}{||l|ccccc||}
\hline \hline \multicolumn{5}{|c||}{$\begin{array}{c}\text { Country pairs that do not share a common land border } \\
\text { and do not speak the same language }\end{array}$} \\
\hline Trade flows & gravity & FE & odds & odds IV & friction \\
\hline CEE exports to EU & 11.3 & 15.8 & 27.4 & 15.7 & 18.9 \\
EU exoprts to CEE & 10.1 & 15.8 & 11.2 & 7.6 & 18.9 \\
Intra EU trade & 3.8 & 6.4 & 6.6 & 4.2 & 6.6 \\
Intra CEE trade & 21.0 & 23.9 & 27.6 & 17.4 & 29.0 \\
\hline \multicolumn{5}{|c|}{ Country pairs that share a common land border } \\
Trade flows & and speak the same language & & \\
\hline CEE exports to EU & gravity & FE & odds & odds IV & friction \\
EU exports to CEE & 6.0 & 6.5 & 7.7 & 5.5 & 6.5 \\
Intra EU trade & 5.4 & 6.5 & 3.2 & 2.7 & 6.5 \\
Intra CEE trade & 2.0 & 2.6 & 1.9 & 1.5 & 2.2 \\
\hline
\end{tabular}

Note: Border effects are computed using estimated coefficients of equations (21), (22), (23) and (24) for each year with industry level data. Effects for countries with no common land border or language are represented.

coefficient of Mills' ratio in the second stage is obtained for the fixed-effects and odds specifications, indicating the necessity of this adjustment. Compared to the results for the aggregate manufactured sector, estimated coefficients are slightly lower for supply and demand variables but larger in absolute terms for distance and common land border. The positive and significant pro-trade effect of a common language spoken by the exporter and the importer appears in all the three specifications compatible with the theoretical model.

Estimated border effects for all trade types and all specifications except the odds are larger when industry level data are employed. This finding testifies that most European trade liberalization was concentrated in a small number of large size industries. The use of aggregate manufacturing data underestimates the amount of 'missing' international trade because it disproportionately reflects large sectors with low barriers to trade. Lower border effects with industry level data and the odds specification are due to the larger selection bias. The odds specification uses domestic trade of the same importing country and in the same industry as reference for international flows. Differently, in gravity and fixedeffects models domestic trade of any country in the sample and any sector may serve as reference after controlling for market supply, demand and trade costs. Therefore, industry level border effects obtained with the odds method are more accurate. The preference over results with the friction model is due to the fact that the odds specification allows for different border effects for CEE exports to core EU and CEE imports from EU.

With industry data the gap between East-West European and intra-EU trade is very prominent under both gravity and odds specifications, the only ones that separate the two types of trade. However, the simple gravity produces erroneous results even when industry level demand and supply data are used because it ignores remote resistance terms implied by the theory, particular strong at the industry level. Different from the aggregate case, with industry data the theoretically consistent odds specification shows that CEE exports 
to EU face higher trade barriers than flows in the opposite direction. This counterintuitive result is robust to changes in the estimation procedure or country panel. The apparent paradox can be explained by the fact that EU countries liberalized first their domestic markets for small and medium size industries, and kept until late 1990s relatively important barriers in several key CEE industries such as textiles and food products, while CEE countries have adopted a distinct policy towards EU partners.

\section{Trade Potential and East-West European Integration}

The important steps undertaken by Eastern and Western European countries for the removal of politically imposed distortions on bilateral exchanges at the beginning of 1990s, as well as efforts engaged with the scheduled EU enlargement translated into a continuous increase in trade between these countries. The drop in European cross-border trade costs is well pictured by the evolution on regional border effects. Figure 1 show that border effects for both CEE-EU and intra-EU trade reduced considerably from 1994 to 2007. This conclusion is reached regardless of the trade specification employed. The odds specification suggests that by the end of the period intra-EU trade costs were less than twice the level of costs for domestic trade, while intra-CEE and CEE-EU trade costs where respectively six and four times larger than this reference level. The reduction of trade costs continued even after CEE countries integrated the European Union.

While strengthening trade between old and new members, EU enlargement affected as well trade between NMS. According to the literature (Maurel, 1998, Gros and Gonciarz, 1996, Baldwin, 1993, Nilson, 2000), the reintegration of CEE countries into the world economy in the early 1990s was accompanied by their disengagement from intraCEE integration. The decline of trade with other CEE partners was beyond its normal level, pointing out the strong competition between former socialist economies for obtaining a higher share of the larger and more attractive core-EU market, and for increasing their chances for accession. With most of CEE countries joining the union, this rivalry has been significantly reduced, and intra-CEE trade has regained attraction. Indeed, as shown in figure 1, intra-CEE border effects dropped by over thirty points from 1994 to 2007.

The reintegration of Central and Eastern European countries in the world economy after the collapse of the communist system was accompanied by the reorientation of their foreign trade towards the European Union. The important drop in CEE-EU border effects in figure 1, especially for CEE exports to core EU countries, reflects this reinforcement of regional integration in Europe.

With the EU enlargement to the East, the convergence of countries from Central and Eastern Europe towards the EU market is expected to arise in all economic areas, including the manner to trade. It is thus not unreasonable to assume that in the perspective the proportion of purchases of domestic relative to foreign products of CEE countries will approach that of the fifteen core EU members. Indeed, intra-EU trade integration remained almost unchanged (figure 1), advocating its use as reference for other regional trade flows. In other words, I assume that in the long run both CEE-EU and intra-CEE trade integration will reach the intra-EU level. Therefore, I compute the level of trade integration across Europe and further increase of these flows (trade potentials) by comparing the trade 
Figure 1: European trade integration: border effects

The fixed-effects specification

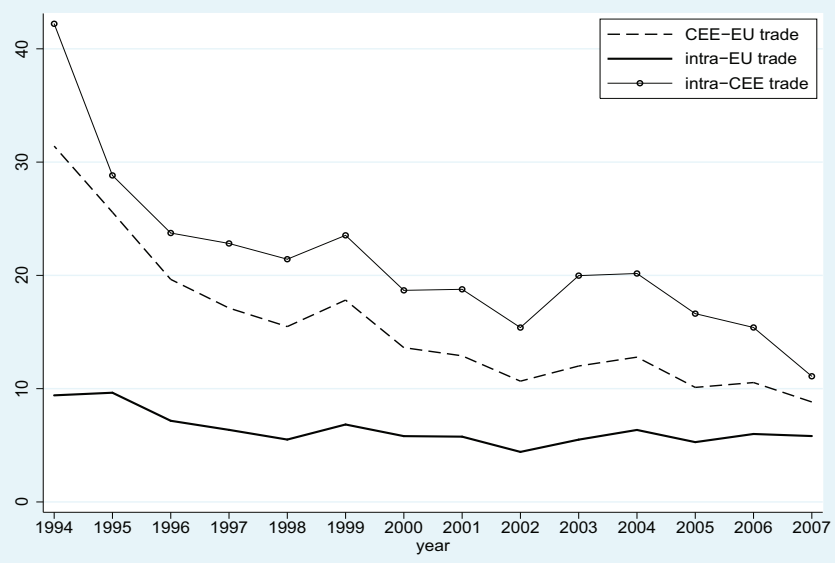

The odds specification

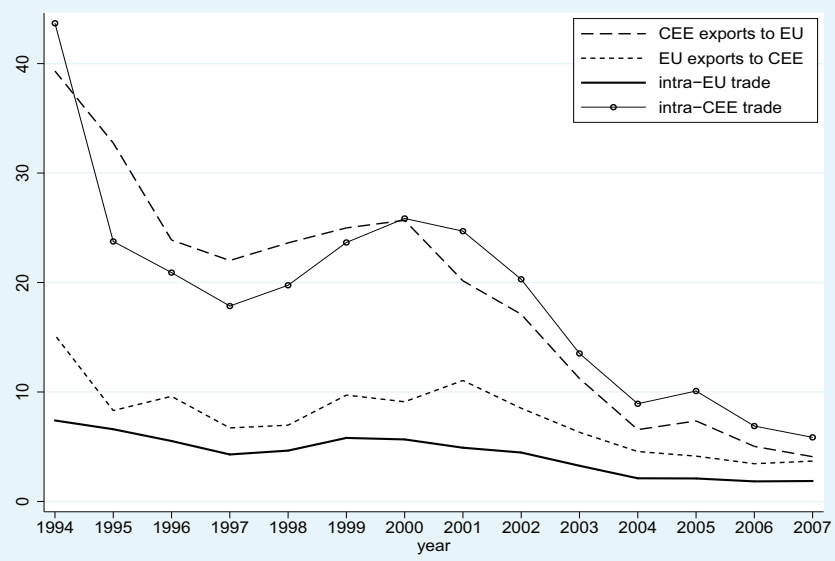

The friction specification

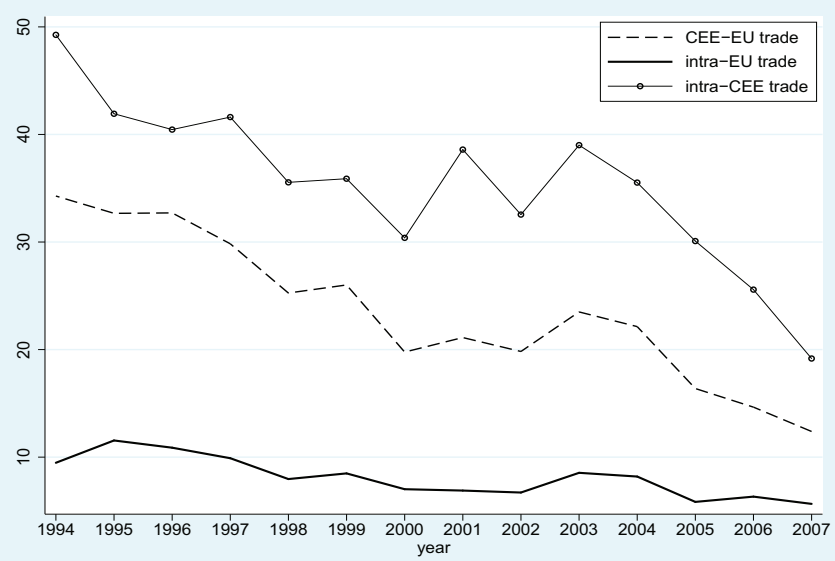

Note: Border effects are computed using estimated coefficients of equations (22), (23) and (24) for each year with industry level data. Effects for countries with no common land border or language are represented. 
costs associated with each trade type to intra-EU costs. I define the potential of CEE-EU and intra-EU trade as the ratio of the corresponding border effects:

$$
\begin{aligned}
\text { CEE-EU trade potential } & =\frac{\text { CEE-EU border effect }}{\text { intra-EU border effect }}, \\
\text { intra-CEE trade potential } & =\frac{\text { intra-CEE border effect }}{\text { intra-EU border effect }} .
\end{aligned}
$$

Trade potentials obtained in this way reflect a trade integration in terms of border effects. This kind of integration reaches its peak when the two groups of countries have identical cross-border trade costs and preferences. I compute trade potentials using equations (25) and (26) and border effect estimates obtained with each of the four trade specifications employed in section 3. Whenever possible, separate border effects for each type of trade (CEE exports to and imports from the EU, and intra-CEE trade) are computed. Average East-West European trade potential for flows in both directions are estimated using a single dummy for CEE-EU trade.

For comparison, I also compute trade potentials using the traditional methods employed in the literature and display the results in table 3. For comparability, I use again trade flows between the old EU countries as reference. Unlike the border effect ratio method presented above, traditional trade potential models rely exclusively on cross-border flows. Therefore I estimate equation (21) on the sub-panel of international trade and use the resulting coefficients to compare CEE-EU and respectively intra-EU trade with the level of intra-EU trade. A fist method, that I call gravity 1, consists in expressing CEE-EU and intra-EU trade flows as percentage of intra-EU flows and attribute the difference up to $100 \%$ to the trade potential. Alternatively, gravity 2 computes trade potentials as the difference between the level of trade predicted by equation (21) and actual trade. Finally, in line with the literature on trade potential, ${ }^{9}$ with gravity 3 I estimate (21) for trade of the reference group, intra-EU trade in our case and use obtained coefficients along with data on production, consumption, bilateral distance, and bilateral linkages (common language and land border) to predict the 'normal' level of trade for the rest of flows. The difference between actual and predicted (or 'normal') trade levels gives the potential of trade. Results with all three methods for the first and last year in the panel are displayed in the upper part of table 3. Trade potentials obtained with the innovative approach introduced in this paper are shown in the last part of table 3. The four rows correspond to the different trade specifications used to estimate European border effects.

A first conclusion that stems from table 3 is that traditional methods employed in the literature, gravity 1, gravity 2 and gravity 3, yield small trade potentials. For all types of trade flows these values are considerably lower than trade potentials obtained with the border effects ratio method. Thus, traditional methods overestimate the level of trade integration in the region. For exampl, according to gravity 1, in 1994 CEE-EU trade represented only $12 \%$ of the level of intra-EU trade for comparable countries, corresponding to a trade potential of $88 \%$. Meanwhile, the ratio of border effects produces a trade potential four times larger. Gravity 2 and gravity 3 find small and non-significant variations

\footnotetext{
${ }^{9}$ Wang and Winters (1991), Hamilton and Winters (1992), Baldwin (1993), Gross and Gonciarz (1996), Fontagné et al. (1999), and Nilsson (2000).
} 
Table 3: European Trade Potential (in \% of actual trade)

\begin{tabular}{|c|c|c|c|c|c|c|c|}
\hline & \multicolumn{7}{|c|}{ Type of trade flows } \\
\hline \multirow[t]{2}{*}{ Method } & CEE to EU & \multicolumn{2}{|c|}{ EU to $\mathrm{CEE}$} & \multicolumn{2}{|c|}{ CEE-EU } & \multicolumn{2}{|c|}{ intra-CEE } \\
\hline & $1994 \quad 2007$ & 1994 & 2007 & 1994 & 2007 & 1994 & 2007 \\
\hline \multicolumn{8}{|c|}{ Traditional trade potential models with international trade flows only } \\
\hline gravity $1^{*}$ & 78 & 76 & 50 & 77 & 58 & 88 & 77 \\
\hline gravity $2^{\dagger}$ & 48 & 52 & 56 & 48 & 52 & 51 & 52 \\
\hline gravity $3 \ddagger$ & 45 & 53 & 52 & 49 & 48 & 50 & 48 \\
\hline \multicolumn{8}{|c|}{ Border effects ratio method: equations (25) and (26) } \\
\hline McCallum (1995) gravity & 253 & 399 & 192 & 409 & 221 & 735 & 388 \\
\hline fixed-effects specification & & & & 334 & 152 & 449 & 191 \\
\hline odds specification & 232 & 204 & 186 & 335 & 209 & 590 & 314 \\
\hline friction specification & & & & 362 & 219 & 520 & 339 \\
\hline
\end{tabular}

in the CEE-EU and intra-CEE trade integration from 1994 to 2007. With trade potentials computed as the difference between gravity-predicted ('normal') and actual volumes of trade, flows between old and new member states and flows within the NMS group in any year during this period are estimated at found to be only $50 \%$ under their potential level. In addition, these models predict slightly larger trade barriers for EU exports to CEE countries than for flows in the opposite direction, a finding contrary to results obtained with the other approaches.

When GDP and population data are used instead of industry-level production and consumption in equation (21), a simplification frequently adopted in the traditional literature, trade potentials predicted by traditional models are even lower (results not displayed). With these adjustments I find that East-West trade integration, if present, was very slow or only marginal. In half of the cases the trade potential for CEE-EU flows increased over the studied period, which comes at odds with the evolution of the regions' economic and political environment. As for intra-CEE trade, this approach does not predict a increased regional integration, but rather a growing reticence of CEE countries to exchange mutually.

The new method for measuring trade potentials introduced above produces similar values with border effects estimated by fixed-effects, odds and friction specifications. This approach situates East-West trade potential in 2007 between 152\% and 219\%. Depending on the trade specification, during the considered period CEE-EU trade regained between $35 \%$ and $48 \%$ of its 1994 potential. The odds specification is the only to produce differentiated results by flows' direction. For all years in the sample the model exhibits CEE exports to EU more distant from their potential than opposite flows. This matches the finding pf lower access of products from Eastern Europe to Western EU markets from the previous section.

According to all three approaches NMS traded very few with each other in the early 
1990s. In 1994 regional intra-CEE trade amounted to $15-18 \%$ of its potential level. Regardless of the border effects estimates used to compute trade potentials in table 3, I find an important increase of the intra-CEE integration. This reflects the drastic reorientation of foreign trade of these countries in the first years following the collapse of the socialist system. Advances in the process of transition and the development of regional economic agreements (CEFTA, the Free Trade Agreement of Baltic states) encouraged regional trade, which augmented enormously in terms of its potential. Lower trade potentials under the fixed-effects specification, compared to odds and friction specifications, are caused by important country specific trade costs encountered by CEE partners (e.g. poor institutions or transport systems) captured by country dummies.

One can also note that using a specification compatible with trade theory is also important. Indeed, considerably larger trade potentials are obtained when one uses border effects estimated with traditional gravity: over $700 \%$ for intra-CEE trade with McCallum (1995) gravity compared to only $450 \%$ with the fixed-effects specification. This difference in results reminds that atheoretical models are subject to non-negligible biases.

The large difference in trade potentials between the upper and lower part of table 3 comes from the use of different criteria for evaluating trade integration. Traditional trade potential models ignore domestic trade and assign 'normal' trade to the prediction of the gravity equation. The method introduced in this paper compares directly trade costs arising in East-West European and intra-CEE transactions to costs existing between EU trade partners. Trade within the domestic market is used as benchmark for the very estimation of these costs. Thus, our method accounts for the discrepancy between domestic and cross-border trade integration. It is important to signal that not all 'missing' international trade is attributed to the trade potential, but only the proportion which corresponds to the difference in trade impediments for specific types of flows. Regional integration is evaluated here in terms of trade costs, expected to converge to the lower intra-EU level. This uniformization of costs will result in increased trade with more distant partners and weaker concentration of trade in the immediate neighborhood.

Larger potentials obtained with the new method confirm the necessity to account for domestic trade in predicting the trade creation effects of regional integration. The disregard of internal trade opportunities is likely to largely underestimate trade potentials. Our method has the advantage of accounting for total international barriers to trade and therefore produces results more in compliance with integration efforts made by countries. Globally, the access of CEE goods to the old EU markets improved considerably during from 1994 to 2007, and a large part of the potential European trade creation was already accomplished. Nevertheless, by the year 2007 the left CEE-EU trade potential was significantly larger than actual trade, implying more than a twofold possible increase of trade in the years to follow.

In table 4 of the Appendix A I show industry-level effects on trade of European integration with the fixed-effects, odds and friction specifications. ${ }^{10}$ The first six columns refer to trade potentials in 1994, and the last six for the year 2007. The first thing to notice is that with a few exceptions trade creation effects are observed for all industries, both CEE-EU and intra-EU trade, and under all specifications. The largest trade creation for both two-

\footnotetext{
${ }^{10}$ The term European integration is used for all 26 European countries considered in this paper. This is different from its wide but inaccurate employment in the literature to designate only EU integration.
} 
way East-West European trade and intra-CEE trade was observed for rubber products and electrical machinery. Non-electrical machinery and iron and steel products also enjoyed important trade creation. Trade between NMS increased largely in industrial chemicals and textiles. The lowest trade integration is found in the tobacco industry, subject to specific domestic regulations especially in core EU countries. In the case of intra-CEE trade, however, this is due to the fact that trade in tobacco production between CEE countries was below its potential level even in 1994. For other chemical products and wearing apparel European trade has even lost some of its potential. This can be explained by the increased competition in these industries with products from emerging Asian countries and in particular China. Moderate effects on trade are obtained for the rest of industries. By the year 2007 CEE-EU trade remains largely inferior to its potential (less than one third) only in seven: food products, beverages, tobacco, chemicals, iron and steel industries, professional and scientific and measuring and controlling equipment, leather products and printing and publishing. As expected, their number is larger for intra-CEE trade.

The reduction of both trade barriers and trade potentials for CEE-EU trade coincided with an even more impressive evolution for trade between NMS. These results disseminate the fears formulated by politicians and some authors that that CEE-EU trade integration will be accompanied by a lower commitment of CEE countries to regional integration, reflected by larger intra-CEE border effects and trade potentials at the beginning of the period. Still, figures in table 3 show that manufactured trade between CEE countries may expand to as much as two to three times the actual volume.

\section{Conclusions}

Trade both between CEE and between CEE and EU countries improved remarkably during the last two decades, both in terms of border effects and trade potentials. The paper shows that there is still place for important growth in bilateral CEE-EU transactions. This result contradicts with most trade potential gravity models that claim that EastWest European trade has already reached its highest integration level. Much higher trade potentials for both CEE-EU and intra-CEE trade are obtained when one controls for the amount of trade within national borders. Results are very robust and are confirmed by three different theoretically compatible trade specifications used. Thus, at the beginning of the twenty-first century trade between CEE and EU countries represented less than half of its attainable level, suggesting a possible $150 \%$ to $200 \%$ increase with further EU integration. As for trade between NMS, its potential ranges depending on the model between $190 \%$ and $340 \%$, despite the strong reduction of bilateral border effects between these countries achieved during the 1990s.

\section{References}

Anderson, J. E. and E. van Wincoop (2003). Gravity with gravitas. American Economic Review. 
Armington, P. (1969). A theory of demand for products distinguished by place of production. IMF Staff Papers (16), 159-176.

Aymo Brunetti, G. K. and B. Weder (1997). Institutional obstacles for doing business. World Bank Research Paper.

Baldwin, R. (1993). The potential for trade between the countries of efta and central and eastern europe. CEPR discussion Paper (853).

Bergsrand, J. H. (1989). The generalized gravity equation, monopolistic competition, and the evolution of the factor-proportions theory. Review of Economics and Statistics 23, $143-153$.

Combes, P.-P., M. Lafourcade, and T. Mayer (2005). The trade creating effects of business and social networks: Evidence from France. Journal of International Economics 66(1), $1-29$.

Deardorff, A. V. (1998). The Regionalization of the World Economy (University of Chicago Press ed.)., Chapter Determinants of Bilateral Trade: Does Gravity Work in a Neoclassical World?, pp. 7-28. NBER. Jeffrey A. Frankel.

Dixit, A. and J. Stiglitz (1977). Monopolistic competition and optimum product diversity. American Economic Review 67(3), 297-308.

Fontagne, Lionel, M. F. and M. Pajot (1999). Le potential d'échanges entre l'union européenne et les peco. Revue Economique 50(6), 1139-1168.

Gros, D. and A. Gonciarz (1996). A note on the trading potential of central and eastern europe. European Journal of Political Economy 12(4), 709-721.

Hamilton, C. and L. A. Winters (1992). Opening up international trade with eastern europe. Economic Policy 14, 77-116.

Head, K. and T. Mayer (2000). Non-europe: The magnitude and causes of market fragmentation in europe. Weltwirtschaftliches Archiv 136(2), 285-314.

Head, K. and J. Ries (2001). Increasing returns versus national product differentiation as an explanation for the pattern of us-canada trade. American Economic Review 91(4), $858-876$.

Krugman, P. (1980). Scale economies, product differentiation, and the pattern of trade. American Economic Review 70(5), 950-959.

Maurel, M. and G. Cheikbossian (1998). The new geography of eastern european trade. Kyklos 51(1), 45-72.

McCallum, J. (1995). National borders matter: Canada-u.s. regional trade patterns. American Economic Review 85, 615-623. 
Nilsson, L. (2000). Trade integration and the eu economic membership criteria. European Journal of Political Economy 16(4), 807-827.

Papazoglou, C., E. J. Pentecost, and H. Marques (2006, 08). A gravity model forecast of the potential trade effects of eu enlargement: Lessons from 2004 and path-dependency in integration. The World Economy 29(8), 1077-1089.

Rauch, J. E. (2001). Business and social networks in international trade. Journal of Economic Literature 39(4), 1177-1203.

Redding, S. and A. J. Venables (2004). Economic geography and international inequality. Journal of International Economics 62, 53-82.

Rose, A. and E. van Wincoop (2001). National money as a barrier to international trade: The real case for currency union. American Economic Review.

Wang, Z. K. and L. Winters (1991). The trading potential of eastern europe. CEPR Discussion Paper (610).

Wei, S.-J. (1996). Intranational versus international trade: How stubborn are nations in global integration. NBER Working Paper (5531).

\section{A Data and additional results}

The empirical application of theoretically derived trade equations encounters both data availability and comparability problems. The use of different classifications, definitions and registration criteria even for such standard economic variables as production and trade may represent an additional source of errors and biases in results. The latter are yet more pronounced in the estimation of border effects when internal trade volumes are computed as the difference between national production and total exports in absence of regional data.

The present study carries over a sample of 27 countries: fifteen core EU members with Belgium and Luxembourg aggregated under a single observation, and twelve Central and East European countries, and a fourteen-year period from 1994 to 2007. Of the twelve CEE countries of the panel ten have joined the EU in May 2004 and two in January 2007. Two levels of aggregation are considered: total manufacturing industry, and 26 product industries according to the ISIC Rev.2 classification.

Data on total manufactured bilateral imports is obtained from the BACI database of Cepii. GDP in current US dollars are from the World Development Indicators (World Bank) database. Total manufacturing and industry-level production, wages, labor force and expenditure are from Eurostat and Trade and Production database of UNIDO (World Bank). Missing Eurostat data are complemented with UNIDO data. In order to ensure compatibility of different data sources, data has been adjusted by applying a conversion rate equal to the average ratio of the value from the base source and the value from the secondary source, and estimated separately for each country on observations present in both databases. Industry-level expenditures are computed as the sum of demand for domestic goods and imports from all trading partners. 
Table 4: Trade potential with respect to intra-EU trade (\% of actual trade)

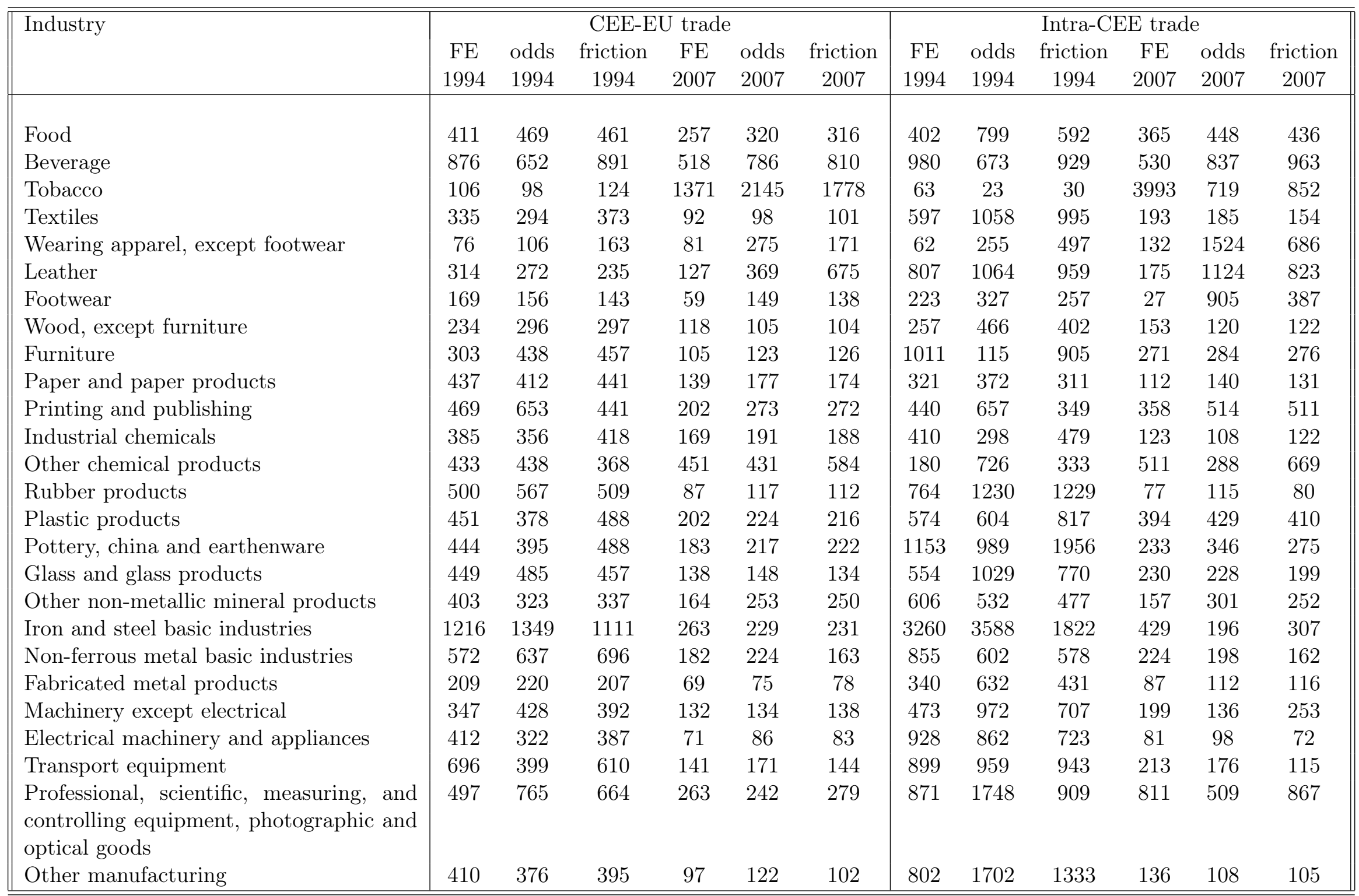

Note: Trade potentials are obtained as in (25) and (26) using border effects obtained with Heckman estimations for each industry. 